\title{
ANALISA GERAKAN KAPAL IKAN BERCADIK SEMI-CIRCULAR DI PERAIRAN PUGER JEMBER
}

\author{
Hery Indria Dwi Puspita
}

Jurusan Teknik Mesin, Fakultas Teknik, Universitas Jember

E-mail : heryindria.teknik@unej.ac.id

Naskah diterima: 03 Desember 2017 ; Naskah disetujui: 28 Desember 2017

\begin{abstract}
ABSTRAK
Kapal ikan di pelabuhan Puger terdiri dari beberapa jenis, salah satunya adalah kapal ikan bercadik. Bentuk dan bahan dari kapal ikan bercadik di Puger hanya terbuat dari bambu, sehingga perlu adanya pengembangan bentuk cadik bambu menjadi bentuk cadik semi-circular untuk menambah kualitas hidrodinamika yang lebih baik. Bentuk pengembangan kapal ikan harus sesuai dengan kondisi di Perairan Puger dan harus memenuhi kapasitas dari faktor keamaaan dan hidrodinamika dari kapal ikan bercadik di Perairan Puger Jember. Oleh karena itu, diperlukan analisa gerak (seakeeping) dari kapal ikan bercadik. Analisa gerak (seakeeping) kapal ikan bercadik tersebut untuk mengetahui kemampuan kapal bertahan dalam kondisi berbahaya saat beroperasi. Kemudian, dari analisa seakeeping dari kapal ikan bercadik semi-circular dapat diketahui peforma dari pengembangan kapal ikan bercadik semi-circular dengan mengadaptasi ukuran utama dari kapal ikan yang telah ada di Puger. Metode yang digunakan adalah dengan pengukuran langsung dimensi utama dari bentuk body dari kapal ikan di perairan Puger Jember. Selanjutnya hasil pengukuran tersebut digambar kembali dengan mengganti bentuk cadik menjadi bentuk cadik semi-circular, dan kemudian dilakukan evaluasi seakeeping kapal ikan bercadik semi-circular. Berdasarkan hasil evaluasi seakeeping kapal memiliki kriteria gerakan heave, pitch, dan roll yang lebih baik dan sesuai dengan kondisi perairan di Puger.
\end{abstract}

Kata Kunci: Hidrodinamika, kapal ikan tradisional, resistance, seakeeping.

\section{PENDAHULUAN}

Kabupaten Jember bagian selatan merupakan wilayah tanjung yang terdapat Tempat Pelelangan Ikan (TPI) dan pelabuhan. Pantai Puger yang berada di Kecamatan Puger merupakan kawasan yang dikenal sebagai TPI yang cukup besar di Kabupaten Jember. Kapal ikan pada umumnya digunakan oleh nelayan di Indonesia terutama nelayan di Kecamatan Puger Kabupaten Jember dalam berlayar menangkap ikan. Terdapat beberapa jenis kapal di pelabuhan Puger terutama kapal bercadik [1]. Pada Gambar 1 menunjukkan kapal ikan tradisional bercadik.

Cadik berfungsi sebagai penyeimbang saat kapal dihantam gelombang. Sehingga, kapal tidak mudah terbalik ketika dihantam gelombang. Kapalkapal bercadik memiliki kemampuan stabilitas yang jauh lebih baik dibandingkan dengan kapal yang tidak menggunakan cadik. Kapal bercadik menggunakan dua cadik yang berada pada kedua sisi kanan dan sisi kiri kapal. Pada saat kapal bergerak, kapal seolaholah menarik kedua cadik dan gaya-gaya bekerja disalurkan melalui lengan kapal. Dalam penelitian ini untuk memperoleh hasil yang maksimal yaitu dengan melakukan pengujian dengan menggunakan model kapal. Pengujian ini dapat digunakan untuk mendukung kinerja perancangan kapal sesungguhnya atau full-scale yaitu dengan menggunakan hasil pengujian hidrodinamika model kapal.

Pada dasarnya kapal ikan bercadik di Puger dibuat dengan hanya memodifikasi desain kapal sebelumnya dengan ketrampilan yang didapatkan dari turun-temurun pendahulunya. Bentuk dan bahan cadik dari kapal ikan bercadik di Puger juga hanya terbuat dari bambu yang dipasang secara memanjang berada pada kedua sisi kanan dan kiri kapal tanpa mementingkan bentuk cadik tersebut. Karena kapal ikan bercadik di Puger tidak melalui proses formal dalam pembangunannya, maka keamanan dari kapal ikan bercadik tersebut saat beroperasi masih perlu dipertanyakan. Menurut Sukadana (2009), cara pembuatan kapal ikan tradisional lebih mengandalkan "insting" dari para pengrajin kapal ikan yang cenderung menghasilkan produk dengan ciri culturebased daripada technology-based product [2]. Meskipun hal tersebut merupakan warisan yang perlu dilestarikan, namun kelemahan yang dimiliki oleh rancangan kapal ikan bercadik di Puger perlu mendapat prioritas, tanpa meninggalkan sisi tradisi secara revolusioner. Oleh karena itu, perlu adanya desain baru kapal bercadik dengan memodifikasi bentuk cadik yang sesuai dengan kondisi di Perairan Puger dan untuk memenuhi kapasitas dari faktor keamaaan dan hidrodinamika dari kapal ikan bercadik 
di Perairan Puger Jember. Dalam penelitian ini bentuk cadik yang dikembangkan adalah bentuk cadik semicircular. Untuk meminimalkan drag gelombang serta diharapkan memiliki olah gerak atau seakeeping yang cukup baik, maka dipilih bentuk cadik semi-circular.

Pada awal abad ke-20 sudah banyak dikembangkan tentang teori gerak kapal. Adanya metode perhitungan koefisien massa tambah dan redaman hidrodinamis benda terapung tiga dimensi maupun dua dimensi. Teori tersebut dilakukan dalam penelitian oleh Lewis (1929) dan Haskind (1946) dengan mempertimbangkan gangguan benda terapung pada medan tekanan gelombang insiden, dan fenomena radiasi. Teori tersebut telah meningkatkan ketelitian hipotesis Froude-Krylov [3][4]. Selain itu, Korvin-Kroukovsky (1955) dan Korvin-Kroukovsky and Jacobs (1957) yang menerapkan konsep gerakan relatif untuk memecahkan masalah refleksi dan difraksi gelombang insiden akibat keberadaan benda [5][6].

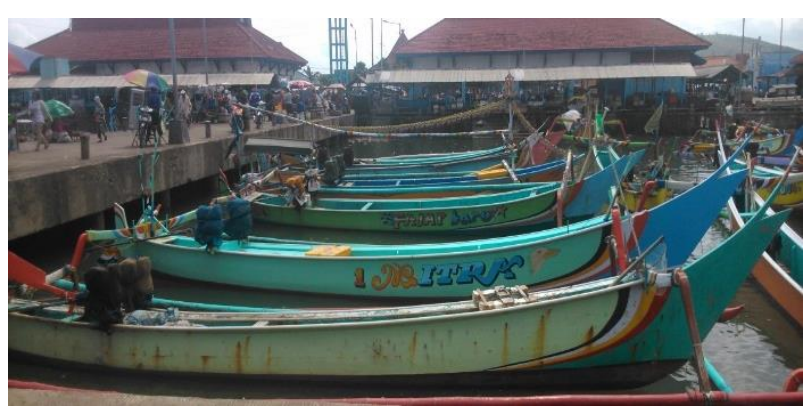

Gambar 1 Kapal Ikan Tradisional Bercadik di Perairan Puger

Gerakan osilasi bangunan apung yang diakibatkan oleh eksistasi gelombang terdiri dari 6derajat kebebasan, dapat dilihat pada Gambar 2. Mode gerakan osilasi tersebut terdiri dari mode gerakan rotasi terhadap sumbu $x, y$, dan $z$ yaitu roll, pitch, dan yaw, serta mode gerakan translasi pada sumbu $x, y$, dan $z$ yaitu surge, sway, dan heave [7]. Gerakan putaran benda apung dimana sumbu acuan menjadi porosnya disebut gerak rotasi, sedangkan gerakan benda apung atau kapal yang sejajar dengan sumbu yang diacu disebut gerakan translasi. Kemudian, untuk gerakan rotasi benda apung yang berporos pada sumbu $x$ disebut mode gerakan roll, untuk gerakan rotasi benda apung yang berporos pada sumbu $y$ disebut mode gerakan pitch, dan gerakan rotasi benda apung yang berporos pada sumbu $z$ disebut mode gerakan yaw. Sedangkan, gerakan translasi dari benda apung atau kapal pada arah sumbu $x$ (maju-mundur) disebut mode gerakan surge, gerakan translasi dari benda apung atau kapal pada arah sumbu y (melintang) disebut mode gerakan sway, dan gerakan osilasi translasi dari benda apung pada arah sumbu $z$ (vertikal) disebut mode gerakan heave [6][8].

Dalam penelitian ini, sebagai langkah awal perlu adanya survey atau mengambilan data untuk mendapatkan data dimensi atau ukuran utama kapal, data bentuk lambung kapal ikan bercadik di Puger, dan lain-lain. Dari data yang diperoleh tersebut dilakukan perancangan kapal ikan bercadik di Puger. Kemudian, dilakukan pula perancangan atau desain baru dari bentuk cadik semi-circular dari kapal ikan bercadik di Puger. Desain baru dari kapal ikan bercadik tersebut juga perlu dilakukan pengujian untuk memprediksi berbagai karakteristik pada kapal tersebut. Dalam pengujian disini, perlu adanya evaluasi dan Analisa seakeeping. Nilai evaluasi dan analisa seakeeping juga merupakan salah satu yang mempengaruhi stabilitas dan untuk mengetahui kemampuan kapal bertahan dalam kondisi berbahaya saat beroperasi. Setelah dilakukan evaluasi dan analisa seakeeping maka dapat ditarik kesimpulan sehingga dapat diketahui kualitas seakeeping kapal ikan bercadik semi-circular. Tujuan dari penelitian ini adalah untuk memperbaiki dan menambah peforma dari kapal ikan bercadik, dan dapat memberikan rekomendasi untuk perbaikan desain cadik kapal ikan Puger yang memiliki kualitas hidrodinamika yang lebih baik atau sesuai dengan perairan Puger sehingga mampu meningkatkan faktor keselamatan nelayan pada saat berlayar dan menangkap ikan. Dalam hal ini adalah dapat digunakan oleh nelayan di Puger untuk mendukung sarana transportasi nelayan serta dapat meningkatkan hasil tangkapan ikan di Perairan Puger Kabupaten Jember.

\section{METODOLOGI}

Analisa gerakan kapal ikan tradisional bercadik diperlukan untuk memenuhi kapasitas dari faktor keamaan dan hidrodinamika. Salah satu faktor hidrodinamika yang dimaksud adalah analisa seakeeping atau olah gerak kapal.

Berikut ini dibahas mengenai langkah-langkah dalam pengerjaan penelitian.

(1) Langkah pertama yang dilakukan adalah pengumpulan data yang dibutuhkan. Data tersebut harus meliputi segala sesuatu yang diperlukan dan berhubungan dalam pengerjaan penelitian ini. Data yang dikumpulkan didapatkan dari wawancara langsung, pengukuran, dan pengamatan di lapangan.

(2) Penggambaran model kapal berdasarkan data dari tipe kapal dari hasil survey dan data untuk pemodelan lambung kapal ikan tipe perairan Puger yang dibuat dengan mengadaptasi bentuk lambung kapal ikan yang telah ada. Kemudian dilakukan perancangan cadik semi-circular dari kapal ikan bercadik Puger yang digunakan untuk diuji evaluasi dan analisa seakeeping. dengan Panjang cadik sebagai berikut:

\section{PANJANG CADIK}

Panjang $=1057 \mathrm{~cm}=10,57 \mathrm{~m}$

Diameter cadik bambu $=14 \mathrm{~cm}=0,14 \mathrm{~m}$ 
Tabel 1 Ukuran Utama Kapal Ikan Tradisional Bercadik di Puger Jember

\begin{tabular}{|c|c|c|c|c|}
\hline Nama Kapal & Panjang (m) & Lebar (m) & Tinggi (m) & Sarat (m) \\
\hline $\begin{array}{c}\text { Kapal Ikan } \\
\text { Bercadik }\end{array}$ & 9,1 & 0,8 & 0,85 & 0,35 \\
\hline
\end{tabular}

Gambar 2 Ukuran Utama Kapal Ikan Tradisional Bercadik di Puger Jember

\begin{tabular}{|c|c|c|c|c|}
\hline Nama Kapal & Panjang (m) & Lebar (m) & Tinggi (m) & Sarat (m) \\
\hline $\begin{array}{c}\text { Kapal Ikan } \\
\text { Bercadik }\end{array}$ & 9,1 & 0,8 & 0,85 & 0,35 \\
\hline
\end{tabular}

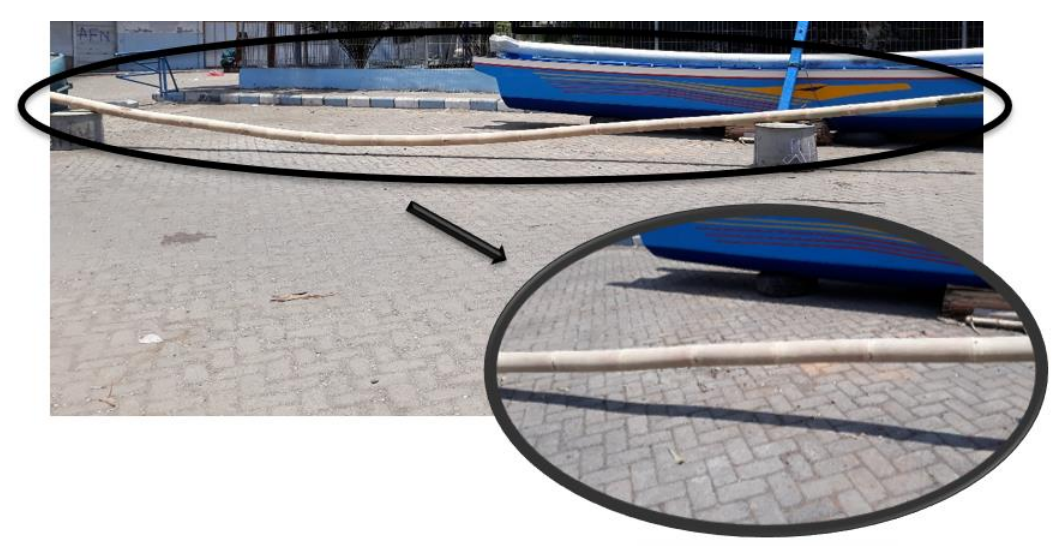

Gambar 2 Sudut Datang Gelombang

(3) Perilaku gerak kapal dipengaruhi oleh gaya-gaya luar yang disebabkan oleh kodisi gelombang disebut seakeeping. Evaluasi seakeeping dilakukan untuk melihat gerak kapal akibat arah gelombang dengan menganalisa kriteria gerakan heave, pitch, dan roll. Hasil prediksi gerakan bangunan apung umumnya ditunjukkan dalam bentuk perbandingan antara amplitudo gelombang insiden dengan amplitudo mode gerakan tertentu, yang berfungsi sebagai fungsi perubahan frekuensi gelombang. Perbandingan amplitudo tersebut disebut Response Amplitudo Operator (RAO). Transfer function yang merupakan fungsi respons gerakan dinamis suatu benda apung yang disebabkan oleh gelombang dengan rentang frekuensi tertentu juga disebut sebagai RAO. RAO merupakan alat untuk mentransfer gaya gelombang menjadi respons gerakan dinamis struktur [9].

Rumus dari RAO dapat dilihat sebagai berikut [10]:

$$
R A O=\frac{\left|\eta_{j}\right|}{\varsigma_{a}}
$$

dimana: $\left|\eta_{j}\right|=$ amplitudo gerakan kapal dalam enam derajat kebebasan

$\varsigma_{a}=$ amplitudo gelombang

Menurut teori klasik gerakan kapal diatas gelombang regular secara matematis mengacu pada hukum Newton ke-2 [11] [12].

(4) Setelah semua tahapan selesai dilaksanakan, selanjutnya dapat ditarik kesimpulan dari analisa dan evaluasi yang telah dilakukan. Kesimpulan berupa nilai hambatan yang dihasilkan dan daya efektif kapal serta peforma dari kapal.

\section{HASIL DAN PEMBAHASAN}

Berdasarkan pengukuran langsung didapatkan ukuran utama kapal ikan tradisional bercadik di perairan Puger. Tabel 1 menunjukkan ukuran utama dari kapal ikan tradisional bercadik. Pada Gambar 2 dapat dilihat bambu yang digunakan untuk cadik kapal ikan tradisional Puger berbentuk tidak melengkung sempurna tetapi ada beberapa lengkungan lain. Sehingga, harus ada pengembangan dari bentuk cadik 
tersebut menjadi bentuk cadik semi-circular. Diameter cadik semi-circular disesuaikan dengan diameter bambu yang telah ada, dapat dilihat pada Gambar 3.

Hasil evaluasi seakeeping yang dihasilkan berupa plot grafik antara encounter wave frequency dengan RAO atau rasio amplitude gerakan kapal dalam enam derajat kebebasan dengan amplitude gelombang. Sudut datang dari gelombang ditunjukkan pada Gambar 4. Analisa karakteristik gerakan-gerakan kapal pada saat berlayar digunakan untuk mengetahui karakteristik hidrodinamika suatu kapal. Dalam penelitian ini karakteristik tersebut disajikan dalam gerakan heave, pitch, dan roll sudut heading $90^{\circ}, 135^{\circ}$, dan $180^{\circ}$ dengan dua variasi kecepatan yaitu $\mathrm{V}=0$ knot dan $\mathrm{V}=7$ knot.

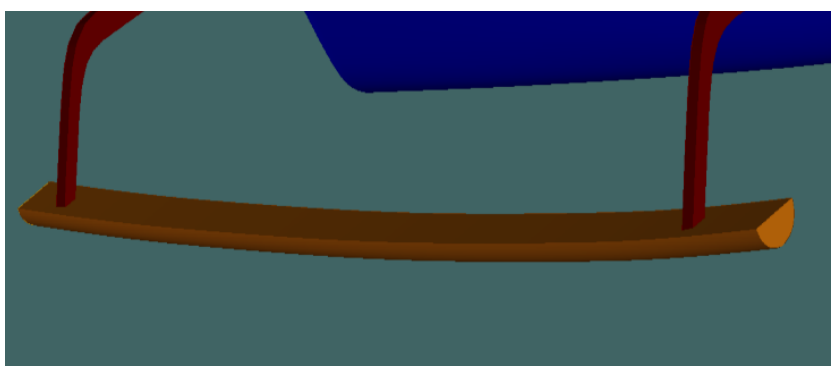

Gambar 3 Sudut Datang Gelombang

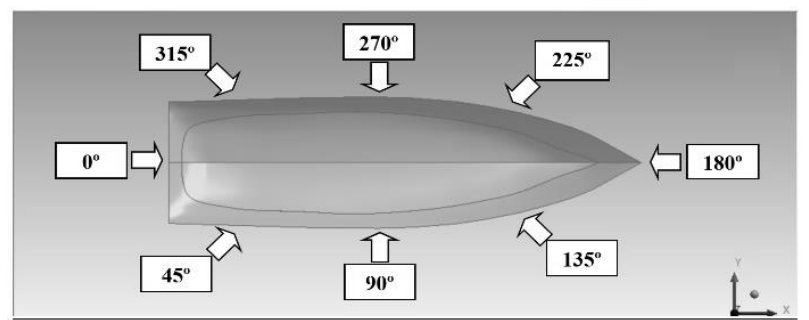

Gambar 4. Sudut Datang Gelombang [13]

Mode gerakan heave dengan kecepatan $\mathrm{V}=0$ knot ditunjukkan pada Gambar 5, dapat dilihat nilai RAO yang dihasilkan untuk kapal dengan cadik circular yang diadaptasi dari diameter kapal cadik bambu ataupun semi circular memiliki nilai yang sama, hal ini dikarenakan besar area cadik yang tercelup adalah sama. Kemudian, pada Gambar 5 menunjukkan RAO maksimum terjadi pada sudut heading gelombang $90^{\circ}$ dengan nilai $1,395 \mathrm{~m} / \mathrm{m}$ pada frekuensi 4,312 rad/s yang ditunjukkan pada garis berwarna biru. Pada Gambar 5 menujukkan kurva untuk kapal dengan cadik circular ataupun semi circular pada sudut $90^{\circ}$ yang dimulai dari nilai RAO $1 \mathrm{~m} / \mathrm{m}$ kemudian pada frekuensi $0,324 \mathrm{rad} / \mathrm{s}$ nilai RAO mulai meningkat sampai $1,395 \mathrm{~m} / \mathrm{m}$ yang menunjukkan nilai RAO maksimum untuk mode gerakan heave. Hal tersebut memberikan informasi yang dapat dipakai sebagai acuan oleh operator, yaitu jika pada suatu saat tertentu ketika berlayar menghadapi gelombang yang relatif besar yang mengarah pada sudut heading $90^{\circ}$ dapat diupayakan untuk bermanuver, sehingga gelombang akan berpropagasi menyilang. Sehingga, intensitas gerakan heave lebih didominasi oleh gelombang sisi atau sudut $90^{\circ}$.

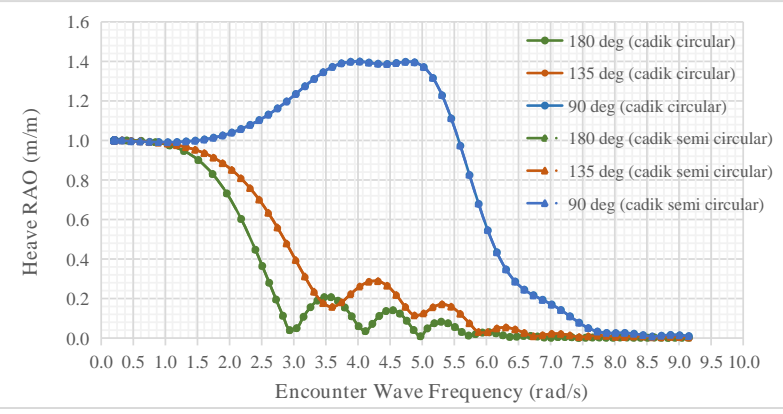

Gambar 5. Response Amplitude Operators (Heave) dengan $\mathrm{V}=0$

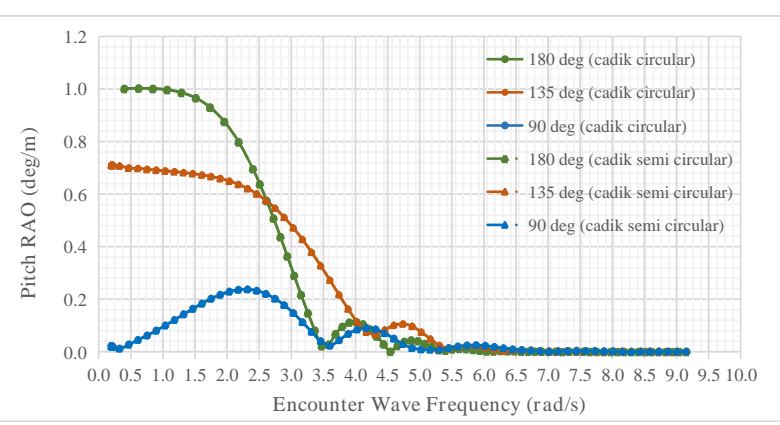

Gambar 6. Response Amplitude Operators (Pitch) dengan $V=0$

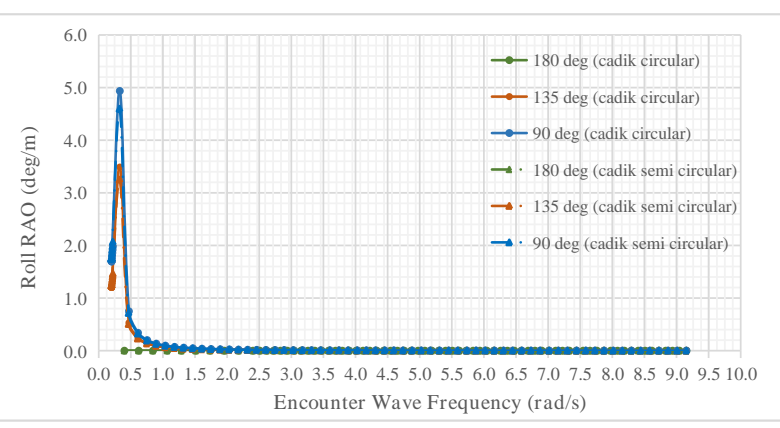

Gambar 7. Response Amplitude Operators (Roll) dengan $\mathrm{V}=0$

Sedangkan, ketika kecepatan diperbesar hingga $\mathrm{V}=7$ knot dapat dilihat pada Gambar 8 kurva heave menunjukkan bahwa kapal dengan cadik semi circular menunjukkan nilai RAO gerakan heave lebih besar dibandingkan nilai RAO gerakan heave pada kapal dengan cadik circular dengan pada sudut datang atau sudut heading $180^{\circ}$. Di sudut $180^{\circ}$ tersebut juga merupakan sudut yang memiliki nilai RAO heave yang maksimum dibandingkan dengan nilai RAO heave pada sudut heading $90^{\circ}$ dan $135^{\circ}$. Pada Gambar 8 menunjukkan kurva untuk kapal dengan cadik circular maupun semi circular pada sudut $180^{\circ}$ dimulai dengan nilai RAO $1 \mathrm{~m} / \mathrm{m}$ namun pada frekuensi 1,29 $\mathrm{rad} / \mathrm{s}$ 
pada kapal dengan cadik circular mulai kurva mulai menunjukkan penurun dan untuk kapal dengan cadik semi circular menunjukkan penurunan pada frekuensi $1,068 \mathrm{rad} / \mathrm{s}$. Sehingga, dapat disimpulkan bahwa yang memiliki nilai heave paling tinggi adalah kapal dengan cadik semi circular pada sudut datang atau heading $180^{\circ}$. Hal tersebut memberikan informasi yang dapat digunakan sebagai acuan, yaitu jika pada suatu saat tertentu ketika berlayar menghadapi gelombang yang relatif besar yang mengarah pada sudut heading $180^{\circ}$ dengan kecepatan kapal $\mathrm{V}=7$ knot dapat diupayakan untuk bermanuver, agar kapal saat berlayar tidak terjadi goncangan akibat gelombang tinggi tersebut. Mengkaji efek dari arah gelombang, intensitas gerakan heave lebih didominasi oleh gelombang haluan yaitu sudut heading $180^{\circ}$. Pada Gambar 8 menunjukkan respons gerakan heave akan jauh lebih mengecil bersamaan dengan propagasi gelombang mengarah dari sisi atau dari sudut heading $90^{\circ}$.

Mode gerakan pitch dengan kecepatan $\mathrm{V}=0$ knot ditunjukkan pada Gambar 6, dapat dilihat bahwa nilai RAO maksimum terjadi pada kapal ikan dengan cadik circular maupun semi circular dengan sudut heading $180^{\circ}$ dengan $1,003 \mathrm{deg} / \mathrm{m}$ pada frekuensi 0,623 $\mathrm{rad} / \mathrm{s}$ yang ditunjukkan pada kurva berwarna hijau. Pada Gambar 6 menunjukkan kurva untuk kapal cadik circular maupun cadik semi circular pada sudut heading $180^{\circ}$ yang dari $1,002 \mathrm{deg} / \mathrm{m}$ kemudian neninggkat hanya $0,001 \mathrm{deg} / \mathrm{m}$ sehingga menjadi $1,003 \mathrm{deg} / \mathrm{m}$ yang menunjukkan nilai RAO maksimum untuk gerakan pitch pada frekuensi $0,623 \mathrm{rad} / \mathrm{s}$. Sehingga menunjukkan intensitas gerakan pitch lebih didominasi oleh gelombang haluan yaitu sudut heading $180^{\circ}$. Respons gerakan pitch akan jauh lebih mengecil bersamaan dengan propoagasi gelombang mengarah ke sisi atau sudut heading $90^{\circ}$.

Berbeda halnya dengan mode gerakan pitch pada kedua kapal dengan kecepatan $\mathrm{V}=7$ knot yang ditunjukkan pada Gambar 9, intensitas lebih didominasi oleh gelombang pada sudut datang $135^{\circ}$. Dapat dilihat bahwa nilai RAO maksimum pada sudut heading $135^{\circ}$ terjadi pada kapal dengan cadik circular dengan nilai RAO pitch maksimum sebesar $8,172 \mathrm{deg} / \mathrm{m}$ pada frekuensi 0,21 rad/s, sedangkan pada kapal dengan cadik semi circular pada sudut heading $135^{\circ}$ dihasilkan nilai RAO pitch sebesar 5,284 deg/m pada frekuensi $0,21 \mathrm{rad} / \mathrm{s}$ pada Gambar 9 dapat dilihat kurva untuk kapal cadik circular pada sudut heading $135^{\circ}$ yang dari 1,601 deg/m meningkat hingga menunjukkan nilai RAO maksimum mode gerakan pitch sebesar 8,172 deg/m, sedangkan untuk kapal cadik semi circular yang dari 1,527 deg/m meningkat hingga 5,284 deg/m. sehingga menunjukkan intensitas gerakan pitch lebih didominasi oleh gelombang pada sudut heading $135^{\circ}$. Respons gerakan pitch akan jauh lebih mengecil bersamaan dengan propagasi gelombang mengarah ke sisi atau sudut heading $90^{\circ}$.

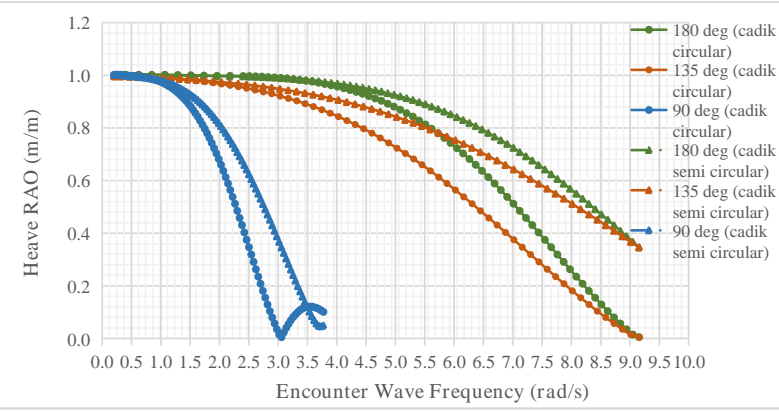

Gambar 8. Response Amplitude Operators (Heave) dengan $\mathrm{V}=7$

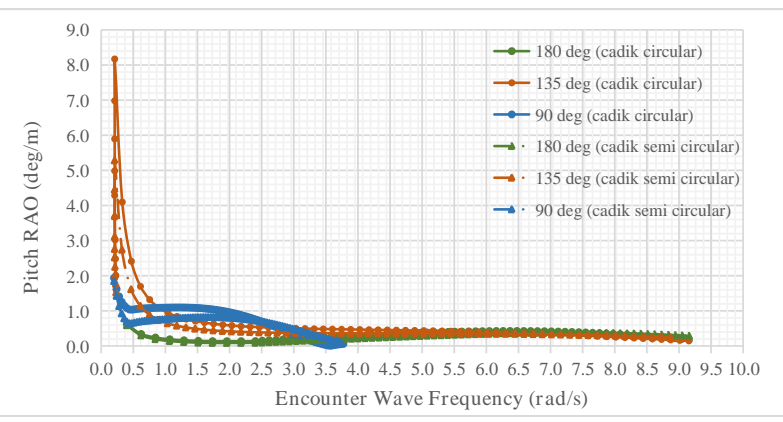

Gambar 9. Gambar 9. Response Amplitude Operators (Pitch) dengan $\mathrm{V}=7$

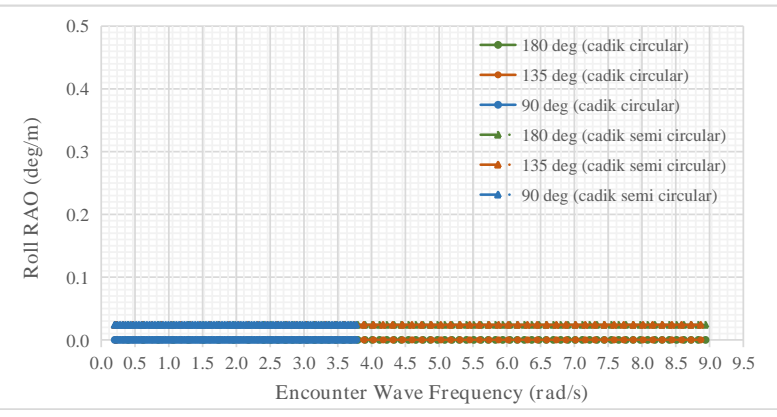

Gambar 10. Gambar 10. Response Amplitude Operators (Roll) dengan $\mathrm{V}=7$

Pada Gambar 7 gerakan roll, RAO maksimum terjadi di kapal cadik circular pada sudut heading $90^{\circ}$ dengan nilai 4,936 deg/m pada frekuensi $0,328 \mathrm{rad} / \mathrm{s}$. Pada Gambar 7 menunjukkan kurva untuk kapal cadik circular pada sudut heading $90^{\circ}$ yang dari nilai RAO gerakan roll 1,983 deg/m kemudian meningkat sampai nilai maksimum 4,936 deg/m yang menunjukkan nilai RAO maksmum untuk mode gerakan roll. Sedangkan untuk kapal dengan cadik semi circular pada sudut heading $90^{\circ}$ yang dari nilai RAO gerakan roll 2,068 $\mathrm{deg} / \mathrm{m}$ kemudian meningkat hingga 4,6 deg/m kemudian menurun yang terlihat seperti Gambar 7. Gambar 7 menunjukkan kapal dengan cadik circular maupun kapal dengan cadik semi circular dalam propagasi gelombang haluan atau sudut heading $180^{\circ}$ tidak terjadi gerakan roll. Dalam hal ini, intensitas 
gerakan roll lebih didominasi oleh gelombang sisi atau sudut heading $90^{\circ}$.

Kemudian, ketika kecepatan V = 7 knot memiliki nilai RAO roll maksimum terjadi pada kapal cadik semi circular pada sudut $90^{\circ}, 135^{\circ}$, dan $180^{\circ}$ dengan nilai konstan 0,024 pada frekuensi $0,185 \mathrm{rad} / \mathrm{s}$ sampai 8,941 $\mathrm{rad} / \mathrm{s}$, dalam propagasi gelombang haluan atau sudut heading $180^{\circ}$ yang sangat kecil, sehingga diharapkan gerakan roll tidak terjadi pula pada kapal ikan bercadik semi circular. Dan pada kapal dengan cadik circular pada $90^{\circ}, 135^{\circ}$, dan $180^{\circ}$ tidak terjadi gerakan roll.

Bila ditinjau dari gerakan kedua kapal ikan tradisional bercadik di Perairan Puger pada gelombang regular, pada dasarnya dapat dikatakan memiliki kualitas olah gerak atau seakeeping yang cukup baik, tidak ada intensitas gerakan kapal yang berlebihan. Secara umum, dilihat dari mode gerakan roll pada kecepatan $\mathrm{V}=0$ knot kapal ikan tradisional bercadik semi circular terlihat lebih baik dibandingkan kapal dengan cadik circular. Namun, ketika kecepatan $\mathrm{V}=7$ knot kapal ikan dengan cadik circular lebih baik. Kemudian, dilihat dari mode gerakan heave dan pitch pada kecepatan $\mathrm{V}=7$ knot kapal ikan bercadik semi circular terlihat lebih baik dibandingkan dengan kapal ikan bercadik circular. Dapat dikatakan bahwa kapal dengan cadik semi circular memiliki karakteristik yang cukup baik dibandingkan dengan kapal ikan dengan cadik circular. Sehingga, untuk kedepannya desain kapal ikan dengan cadik semi circular dapat dikembangkan untuk mendapatkan karakteristik seakeeping atau olah gerak kapal yang baik yang sesuai dengan kondisi perairan Puger.

\section{KESIMPULAN}

Berdasarkan pengembangan model, hasil evaluasi seakeeping yang dialami oleh kapal ikan bercadik circular yang diadaptasi dari cadik bambu dengan menyesuaikan diameter dari bambu dan hasil evaluasi seakeeping kapal ikan bercadik semi circular, dapat ditarik kesimpulan bahwa kapal ikan tradisional bercadik semi circular memiliki karakteristik seakeeping yang cukup baik dibandingkan dengan kapal ikan dengan cadik circular. Sehingga, kapal ikan bercadik semi circular dapat dikembangkan di Perairan Puger Jember.

\section{DAFTAR PUSTAKA}

[1] H. I. D. Puspita, "Studi Karakteristik Hidrodinamika Kapal Ikan Tradisional di Perairan Puger Jember," M.T. Tesis, ITS, Surabaya. Jul. 2016.

[2] I. B. P. Sukadana, "Studi Eksperimental Tahanan Kapal Ikan Tradisional Jenis Payang di Jawa Timur," Seminar Nasional Pascasarjana IX-ITS, ISBN No. 978-979-96565-5-1, 2009.

[3] F. M. Lewis, "The Inertia of Water Surrounding a Vibrating Ship," Transactions of SNAME, vol. 37, hal. 1-20, 1929.

[4] M. D. Haskind, "The Hydrodynamic Theory of a Ship in Rolling and Pitching," Technical Reseacrch Bulletin, no. 1-12, hal. 3-43, 1946.

[5] B. V. Korvin-Kroukovsky, "Investigation of Ship Motions in Regular Waves," Transactions of SNAME, vol. 63, hal. 386-435, 1955.

[6] B. V. K. Kroukovsky, and W.R. Jacobs, "Pitching and Heaving Motions of a Ship in Regular Waves," Transactions of SNAME, vol. 63, hal. 590-632, 1957.

[7] E. B. Djatmiko, Perilaku dan Operabilitas Bangunan Laut di Atas Gelombang Acak, Surabaya: ITS Press, 2012.

[8] R. Bhattacarya, Dynamics of Marine Vehicles, New York: John Wiley \& Sons, 1978.

[9] S. K. Chakrabarti, Hydrodynamics of Offshore Structures, Southampton: Computational Mechanics Publications, 1987.

[10] O. M. Faltinsen, Hydrodynamics of High-Speed Marine Vehicles, Cambridge: Cambridge University Press, 2005.

[11] W. Froude, "On the Rolling of Ships," Transactions of INA, vol. 2, 1861.

[12] A. N. Krylov, "A New Theory of the Pitching Motion of Ships on Waves and of the Stresses Produced by This Motion," Transactions of INA, vol. 37, 1896.

[13] H. I. D. Puspita, dan I. K.A. P. Utama, "Studi Karakteristik Hidrodinamika Kapal Ikan Tradisional di Perairan Puger Jember," Jurnal Kelautan Nasional, vol. 12, no. 1, 2017. 